Sessions include:

- Concomitant Ablation-How I Do It and Why

- Hybrid Ablation and Other Alternative Approaches for Lone Atrial Fibrillation

- Lead Extraction: Modern Techniques in Management of Complications

- Management of the Left Atrial Appendage

- Mechanisms of Atrial Fibrillation

- Special Issues and Controversies in Surgical Ablation

- Surgical Ablation Guidelines

- Surgical Treatment of Arrhythmias: The Basics

- Surgical Treatment of Lone Atrial Fibrillation: How I Do It

- Ventricular Tachycardia Ablation

Program Directors

Ralph J. Damiano, Jr

A. Marc Gillinov

Program Committee

Niv Ad

Vinay Badhwar

Manuel Castella

James L. Cox

Mark LaMeir

Patrick M. McCarthy

Takashi Nitta

Harold G. Roberts

Richard Schuessler

Register and Reserve Housing: www.aats.org/stars

\section{Don't Miss the 2017 AATS International}

\section{Cardiovascular Symposium}

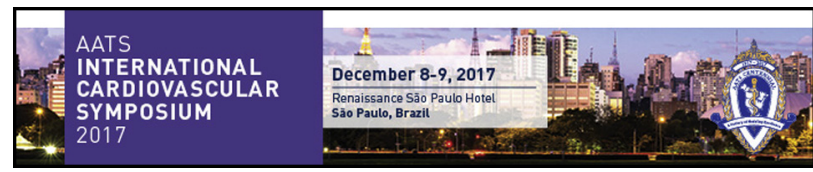

December 8-9, 2017

Renaissance São Paulo Hotel

São Paulo, Brazil

Join renowned cardiologists and surgeons at the 2017 AATS International Cardiovascular Symposium in São Paulo, Brazil, on December 8-9, 2017, to advance your clinical knowledge in heart valve disease-aortic and ascending aorta, coronary, mitral, pulmonary, and tricuspid.

The two-day symposium will bring together international leaders to discuss state-of-the-art information on devices, long-term results, and surgical techniques with a focus on preventing, diagnosing, and treating heart valve disease.
Program Directors

Joseph S. Coselli

Walter J. Gomes

Marc R. Moon

Thoralf M. Sundt III

For more information, go to: aats.org/ics

\section{AATS Mechanical Circulatory Support Symposium: 21st Century State-of-the-Art Treatment of Advanced Heart and Lung Failure}

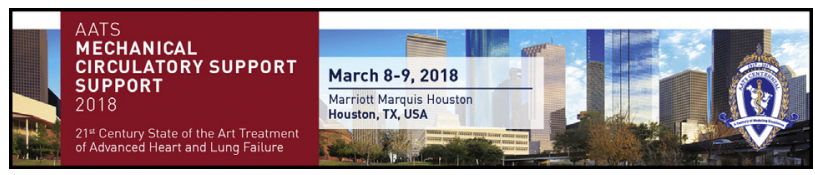

SAVE THE DATE

March 8-9, 2018

Marriott Marquis Houston

Houston, TX, USA

Program Directors

Shaf Keshavjee

Jeffrey A. Morgan

Francis D. Pagani

Mark S. Slaughter

The Mechanical Circulatory Support Symposium focuses on the 21st century state-of-the-art treatment of advanced heart and lung failure. Experts in the field will lead this two-day meeting covering mechanical circulatory support/ LVADs, ECMO, and heart and lung transplantation topics. The program is designed to bring LVAD/transplant cardiac surgeons, heart failure cardiologists, pulmonologists, anesthesiologists, and industry representatives together for much-needed discussions.

\section{Sessions Include:}

- Bridge Strategies With Short-Term Devices

- Complications Using Long-Term MC

- Controversial Topics With Long-Term Device Therapy

- ECMO for Respiratory Failure

- MCS Device Thrombosis

- Minimally Invasive LVAD Insertion, Concomitant Procedures

- Patient Selection and Optimization for Long-Term MCS Devices

- The Role of ECLS in Lung Transplantation 